University of South Florida

DIGITAL COMMONS

Digital Commons @ University of

@ UNIVERSITY OF SOUTH FLORIDA

South Florida

School of Geosciences Faculty and Staff

Publications

School of Geosciences

1995

\title{
Inflation of Long Valley Caldera from One Year of Continuous GPS Observations
}

\author{
Frank H. Webb \\ California Institute of Technology \\ Marcus Bursik \\ State University of New York \\ Timothy H. Dixon \\ University of Miami, thd@usf.edu \\ Frederic Farina \\ University of Miami \\ Grant Marshall \\ U.S. Geological Survey
}

See next page for additional authors

Follow this and additional works at: https://digitalcommons.usf.edu/geo_facpub

Part of the Earth Sciences Commons

\section{Scholar Commons Citation}

Webb, Frank H.; Bursik, Marcus; Dixon, Timothy H.; Farina, Frederic; Marshall, Grant; and Stein, Ross S., "Inflation of Long Valley Caldera from One Year of Continuous GPS Observations" (1995). School of Geosciences Faculty and Staff Publications. 497.

https://digitalcommons.usf.edu/geo_facpub/497

This Article is brought to you for free and open access by the School of Geosciences at Digital Commons @ University of South Florida. It has been accepted for inclusion in School of Geosciences Faculty and Staff Publications by an authorized administrator of Digital Commons @ University of South Florida. For more information, please contact digitalcommons@usf.edu. 


\section{Authors}

Frank H. Webb, Marcus Bursik, Timothy H. Dixon, Frederic Farina, Grant Marshall, and Ross S. Stein 


\title{
Inflation of Long Valley Caldera from one year of continuous GPS observations
}

\author{
Frank H. Webb \\ Jet Propulsion Laboratory, California Institute of Technology, Pasadena \\ Marcus Bursik \\ Department of Geology, State University of New York, Buffalo \\ Timothy Dixon and Frederic Farina \\ Rosenstiel School of Marine and Atmospheric Science, Division of Marine Geology and Geophysics, University of Miami \\ Virginia Key, Florida
}

Grant Marshall and Ross S. Stein

U.S. Geological Survey, Menlo Park, California

\begin{abstract}
A permanent Global Positioning System receiver at Casa Diablo Hot Springs, Long Valley Caldera, California was installed in January, 1993, and has operated almost continuously since then. The data have been transmitted daily to the Jet Propulsion Laboratory for routine analysis with data from the Fiducial Laboratories for an International Natural sciences Network (FLINN) by the JPL FLINN analysis center. Results from these analyses have been used to interpret the on going deformation at Long Valley, with data excluded from periods when the antenna was covered under 2.5 meters of snow and from some periods when Anti Spoofing was enforced on the GPS signal. The remaining time series suggests that uplift of the resurgent dome of Long Valley Caldera during 1993 has been $2.5 \pm 1.1 \mathrm{~cm} / \mathrm{yr}$ and horizontal motion has been $3.0 \pm$ $0.7 \mathrm{~cm} / \mathrm{yr}$ at $\mathrm{S} 53 \mathrm{~W}$ in a no-net-rotation global reference frame, or $1.5 \pm 0.7 \mathrm{~cm} / \mathrm{yr}$ at $\mathrm{S} 14 \mathrm{~W}$ relative to the Sierra Nevada block. These rates are consistent with uplift predicted from frequent horizontal strain measurements. Spectral analysis of the observations suggests that tidal forcing of the magma chamber is not a source of the variability in the $\mathbf{3}$ dimensional station location. These results suggest that remotely operated, continuously recording GPS receivers could prove to be a reliable tool for volcano monitoring throughout the world.
\end{abstract}

\section{Introduction}

In January, 1993, a GPS receiver was permanently stationed atop the resurgent dome in Long Valley Caldera, California (Figure 1), as part of a project to develop GPS as a tool for measuring deformation in volcanic areas by deploying GPS receivers for continuous, semi-continuous, and epochal observations. Long Valley Caldera was chosen because of its combination of scientific interest, high activity, and preexisting monitoring programs against which our results could be compared.

Copyright 1995 by the American Geophysical Union.

Paper number 94GL02968

0094-8534/95/94GL-02968\$03.00
Unrest at Long Valley Caldera has continued since earthquakes in 1978 heralded a time of episodic seismic and deformational activity [Hill et al., 1985]. Leveling surveys in the early to mid-1980s revealed that the resurgent dome in the central part of the caldera was uplifting at rates up to $20 \mathrm{~cm} / \mathrm{yr}$. More recently, static GPS surveys from 1988 to 1992 are consistent with an average uplift rate of $2.5 \mathrm{~cm} / \mathrm{yr}$ [Dixon et al., 1993], while two-color laser geodimeter measurements indicate that the deformation rate is in fact highly variable [Langbein, 1989]. Episodes of high strain rate and seismic energy release have occurred in 1980, 1983, and 1989-90. Geodimeter measurements suggest that the most recent episode of deformation which began in 1989 continues to the present at somewhat reduced rates from the 1989-1990 levels [Hill et al., 1990; Langbein et al., 1993].

The present contribution reports on the results from the continuously operating GPS receiver at Casa Diablo Hot Springs near the southern boundary of the resurgent dome (CASA in Figure 1). To date, more than 300 days of continuous observations from CASA have been made.

\section{GPS Analysis}

A dual frequency, P-code TurboRogue GPS receiver and antenna were installed on January 15, 1993, at CASA, where the USGS operates a two-color geodimeter for measuring horizontal strain to reflectors stationed around the caldera. Geodimeter measurements are made several times a week, year round. The GPS receiver at CASA is housed in the geodimeter building, which provides shelter, power, and communications. A choke ring antenna is mounted on a newly constructed monument about $80 \mathrm{~cm}$ above the ground surface and enclosed in a small ray dome for protection.

The receiver is remotely controlled via telephone and is accessed on a daily basis from JPL. Each day the receiver is automatically phoned and the GPS data downloaded via high speed modem. The data are then routinely processed for station coordinates as part of a global network solution. More than $\mathbf{4 0}$ globally distributed stations are processed at JPL as part of the FLINN GPS Network using the GPS Inferred Positioning System (GIPSY) software developed at JPL [Zumberge, et al., 1994]. The lag time between data collection and the determination of solutions is about two weeks due mostly to 


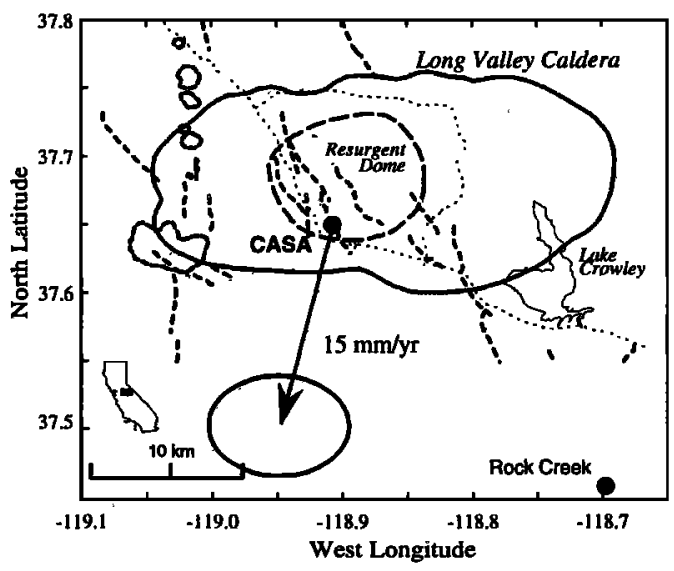

Figure 1. Map of Long Valley Caldera showing the caldera boundary, resurgent dome, the Rock Creek weather station, and the location of the Inyo Craters and Mammoth Mountain. Roads are shown as dashed-dotted line. The vector $(1.5 \pm 0.7$ $\mathrm{cm} / \mathrm{yr}$ at $\mathrm{S} 14 \mathrm{~W}$ ) is the horizontal motion of CASA with respect to the Sierra Nevada using the model of Argus and Gordon [1991] for Sierra Nevada-North America relative motion. The error ellipse is the $95 \%$ confidence region scaled by $\chi^{2}$ divided by the number of degrees of freedom, $\chi^{2} \mathrm{v}$.

delays in obtaining data from some of the global network sites.

In the daily FLINN analyses, the data are first processed using the TurboEdit algorithm [Blewitt, 1990] to a) repair losses of lock, b) remove points flagged as bad by the receiver, c) form the ionosphere free data type, and d) reduce the data volume to 10 -minute points. Each 10 -minute point is a smoothed, ionosphere free pseudorange measurement and a decimated ionosphere free carrier phase observation for every satellite-station pair observed.

The GPS observations are filtered using a Square Root Information Filter [Lichten, 1990]. Satellite epoch states and ground station coordinates are estimated as constants. Satellite and station clocks, zenith troposphere delays, carrier phase biases, and solar radiation pressure are estimated as stochastic processes. The clocks and carrier phase biases are treated as white noise processes. Except for one clock that is used as a reference, the clocks are reset at every epoch, and the satellite-station carrier phase biases are reset whenever an unrepaired loss of lock was detected in the preprocessing.

The data from CASA are processed together with the global network data using a fiducial free strategy. In this strategy, loose, $1 \mathrm{~km}$, constraints are applied to the a priori station locations every day, allowing the reference frame for resulting station coordinate estimates and their covariances to be defined by the GPS data. Such solutions have been shown to define a stable global network polyhedron of stations that has welldefined inter station lengths, but lacks a network orientation that is consistent from day to day [Heflin, et al., 1992]. The orientation is acquired by applying fiducial constraints after the GPS analyses. Thus, any set of fiducial stations that is a subset of the stations in common among all of the days processed can be chosen without reprocessing all of the GPS data.

For these analyses, a globally distributed fiducial network was chosen (Table 1), with coordinates in the International Terrestrial Reference Frame '91 (ITRF91). ITRF91 is a space geodetic system that contains results from 20 years of VLBI and SLR observations and 2 years of GPS observations, and is accurate at the level of 1 part in $10^{9}$ [Boucher et al., 1992]. It is defined at epoch 1992.5 and contains both station coordinates and velocities, which were used to map the fiducial coordinates to their values on each day processed.

While this strategy applies fiducial constraints consistently for all days using a highly precise reference system, there remains some variability in the quality of the solutions on particular days. Some of these effects degrade the solution for the entire network and others are local to particular stations. At CASA these problems are primarily due to systematic mis-modeling of the GPS signal and the results from these days have been excluded from the geophysical interpretation as explained below.

The most significant network effect is from data collected under Anti-Spoofing (AS). AS is the technique used by the Department of Defense, which operates GPS, to encrypt the Pcode transmitted by the satellites. This signal is used by the receivers to calculate the precise pseudorange measurements. Under AS, only authorized users can receive the P-code. In the global network, including CASA, no P-code data are collected by the receivers. Instead, the receivers form a combination of less precise C/A code and cross correlated P-code observations to form P-code like data types. Initially, these data types were edited as P-code data. Because the automatic data editing routine had not been tuned for AS data, this caused some analysis problems when AS was in effect. The strategy resulted in mis-modeling of the GPS observations as indicated by the relatively poor estimates of station coordinates and the relatively large post-fit residuals between the GPS observations and the model observations. Because of this, results from 40 days when AS data were improperly edited have been excluded from the time series of station coordinates.

The other significant unmodeled noise source is local to CASA. Snow depth in the area during the winter of 1992-3 exceeded 3 meters, with an accumulation of as much as 2.5 meters on top of the ray dome protecting the antenna. While the receiver continued to track through the snow, the effect of the snow on the signal was not modeled. The results show large horizontal and vertical biases during the months when the antenna was buried, with the biases increasing with snow depth. Figure 2 shows the vertical component of the station coordinates for CASA. Data for all days except those when AS was on are shown. The RMS postfit carrier phase residuals from the GPS analyses and the equivalent water content for the closest snow course at Rock Creek (Figure 1) are also plotted. The postfit residuals correlate well with the largest deviations from the mean vertical positions and with the period of largest snow accumulation.

Table 1. Fiducial stations used and their ITRF91 coordinates

\begin{tabular}{lrrr}
\hline STATON & LATTUDDE & \multicolumn{1}{c}{ LONGTUDE } & \multicolumn{1}{r}{ HEIGHT (M) } \\
\hline ALGO & 45.955800 & -78.071365 & 200.8764 \\
FAIR & 64.978002 & -147.499238 & 319.0111 \\
HART & -25.887104 & 27.707760 & 1555.3554 \\
KOKB & 22.126259 & -159.664921 & 1167.3643 \\
MADR & 40.429160 & -4.249661 & 829.4952 \\
SANT & -33.150290 & -70.668557 & 723.0369 \\
TROM & 69.662747 & 18.938326 & 132.4505 \\
YAR1 & -29.046560 & 115.346973 & 241.2768 \\
\hline
\end{tabular}




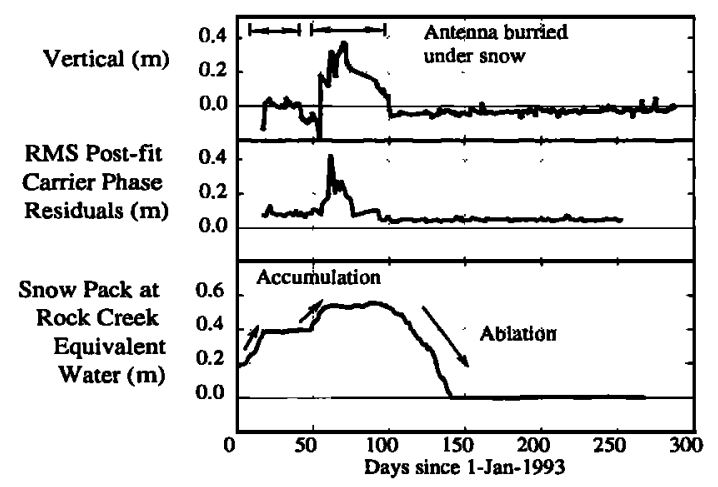

Figure 2. The top figure shows the vertical station coordinate for all days analyzed except for days when AS data were improperly edited. (AS has been turned on continuously since Jan. 31, 1994.) Periods when the antenna was buried in snow are indicated by the arrows at the top of the plot. The middle plot shows the RMS carrier phase postfit residual for CASA for the same time period. Postfit residuals are the difference between the observed carrier phase and the modeled value after all of the parameters have been estimated. The bottom plot shows the snow pack at Rock Creek from the California Department of Water Resources. Snow pack represents the equivalent amount of water in a column of snow. Periods of snow accumulation and ablation are indicated. The large postfit residuals when the antenna was buried under snow indicate that results from this period were mis-modeled and are not representative of the true station height.

The first day (Day 16) is the day the antenna and receiver were installed. The monument had to be dug from under $1 \mathrm{~m}$ of fresh snow. One meter of wind-blown snow was again removed on Day 44. The antenna remained uncovered for several days until the next snowfall. It remained buried under as much as 2.5 $\mathrm{m}$ of snow until day $\sim 100$ when the snow had melted below the base of the antenna. (The exact day when the snow melted below the antenna is uncertain, but has been inferred from a combination of snow pack records and visual reports.) Because the effects of snow are not modeled, the GPS results from the days when the antenna was snow-covered have been excluded from the interpretations, including days 16-41 and 48-100.

\section{Results}

Figure 3 shows that the velocity of CASA moves at a significant rate with respect to the global reference frame. (Latitude and longitude contain contributions from unmodeled plate motions and intraplate motions, and are of secondary interest in the present study.) Assuming that the contributions to the vertical component by plate motions are negligible, then the uplift rate at CASA is $2.5 \pm 1.1 \mathrm{~cm} / \mathrm{yr}$. This rate is consistent with the continuation of vertical deformation at a rate similar to those inferred or measured in the immediate past. Leveling surveys at Long Valley [Yamashita et al., 1992] suggest $8-11 \mathrm{~cm}$ of uplift of the resurgent dome relative to points outside the caldera between November, 1988 and August, 1992, at an average rate of $\sim 3 \mathrm{~cm} / \mathrm{yr}$. It is expected that the rate after late -1989 , when horizontal strain rates accelerated, is higher than that for the preceding period. Uplift rates inferred from geodimeter measurements [Langbein et al., 1993a] suggest an uplift of $11 \mathrm{~cm}$ from mid-1989 to late1991 from deformation within the geodimeter network,

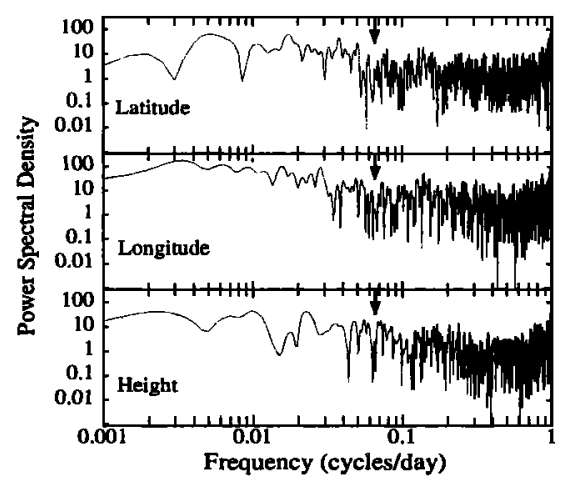

Figure 3. Shown are the time series of station height, latitude, and longitude plotted as differences from the mean values after days of improperly edited AS data and snow cover have been removed. The $1 \sigma$ formal errors are plotted for each point, except those with formal errors $>5 \mathrm{~cm}$, which are not shown for clarity. Solid straight lines are linear fits to the station coordinates. Rates are shown with their $95 \%$ confidence limits scaled by $\chi^{2} v$ to account for mis-fit between the estimated trend and the data.

suggesting a rate of $\sim 5 \mathrm{~cm} / \mathrm{yr}$. Refinement of this model [Langbein et al., 1993b] using leveling data from late 1988 and mid-1992 shows $8 \mathrm{~cm}$ of uplift of the resurgent dome during that period $(\sim 4 \mathrm{~cm} / \mathrm{yr})$. The effects on the uplift rate of fluid withdrawal by the geothermal project at Casa Diablo Hot Springs, if any, cannot be measured with the single GPS receiver at CASA. However, leveling [Langbein et al., 1993b]

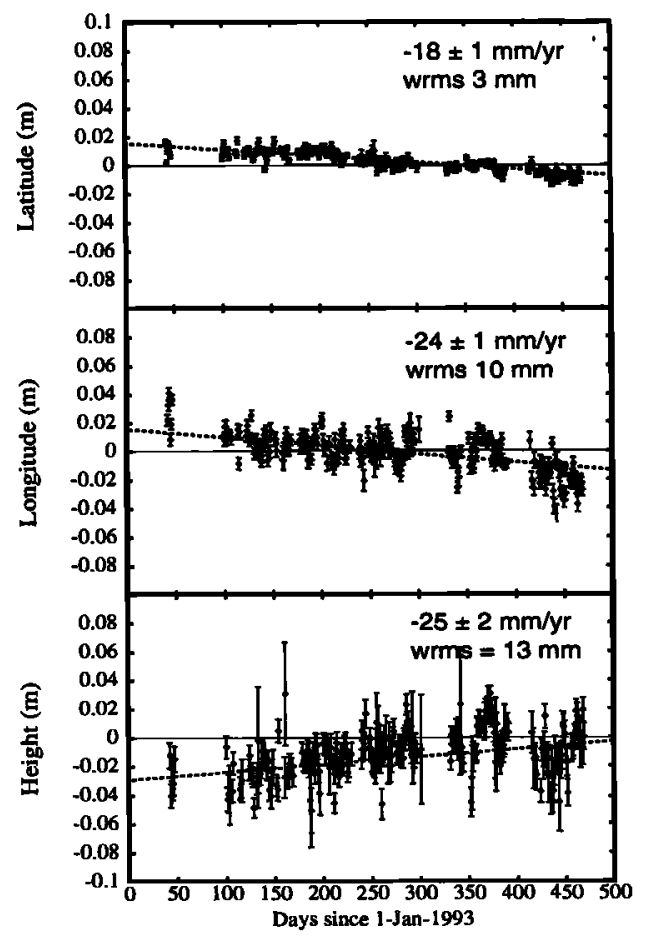

Figure 4. The power spectra for the three GPS components show no distinct power maxima. The arrow is at a period of 14.7 days, corresponding to what should be a peak if magmatic activity at Long Valley were phase-locked with the solid-earth tides. The typical solid-earth tide signal is removed during normal GPS processing. 
indicates that the effects of the withdrawal are negligible at CASA, because the cone of subsidence is confined within 1.5 $\mathrm{km}$ of the extraction well, while CASA is over $7 \mathrm{~km}$ from the well.

Both periodic components, generally resulting from tidal forcing [Dzurisin, 1980], and chaotic components [Cortini et al., 1991, 1993] of activity including deformation have been noted at restless volcanoes, including silicic tuff calderas similar to Long Valley. Because of the good temporal coverage provided by these continuous measurements, the spectra for each of the spatial components can be used to test for the presence of such motions at Long Valley. In the global GPS analyses, solid earth tides are removed from the station coordinate estimates. The spectra were formed on the residual vertical, latitudinal and longitudinal components by first removing the mean value and the linear trend from the time series shown in Figure 3. To account for the unevenly sampled series, these spectra were calculated using the Lomb Method described in Press et al. [1992]. Figure 4 shows that there are no correlated peaks in power between the three time series, and certainly none at multiples of the 14.7 day peak in tidal power [Dzurisin, 1980]. The power spectral density of the vertical component is particularly flat, suggesting that the frequency signal consists of uncorrelated noise. This behavior is consistent with spectral analyses from similar time series for stations in the global FLINN GPS network [M. B. Heflin, personal communication]. Thus, within the limitations of the data that we have gathered, forcing of the deformational signal by tides or other similar periodic forces is not yet discernible.

\section{Conclusions}

Results of the continuous GPS survey at CASA suggest that through September, 1993, the resurgent dome of Long Valley caldera has continued to uplift at a rate comparable to rates that have been measured or inferred over the past five years. Vertical deformation associated with magmatic processes can yield some of the most useful data for understanding the nature of magmatic activity [Cortini et al., 1991, 1993]. The GPS data at Long Valley provide an important addition to other monitoring information, particularly in light of the paucity of vertical deformation data over the past five years at this restless volcano. Remotely operated, continuously recording GPS receivers offer a valuable tool for volcano monitoring, particularly when unrest precludes operators from working on the volcanic edifice.

Acknowledgments. The authors thank the JPL FLINN analysis team for their support and Dave Hill, Roger Denlinger, and two anonymous reviews for their helpful reviews of the manuscript. The work described in this paper was carried out in part at the Jet Propulsion Laboratory California Institute of Technology, under contract with NASA.

\section{References}

Argus, D., and R. G. Gordon, Current Sierra Nevada-North American motion from very long baseline interferometry: Implications for the kinematics of the western United States, Geology, 19, pp 1085-1088, 1991.

Blewitt, G., An automatic editing algorithm for GPS data, Geophys. Res. Lett., 17, 199-202, 1990.
Boucher, C., Z. Altamimi and L. Duhem, "ITRF91 and its associated velocity field", IERS Tech.Note 12, Obs. de Paris, October, 1992.

Cortini, M., Cilento, L. and A. Rullo, Vertical ground movements in the Campi Flegrei caldera as a chaotic dynamic phenomenon, Jour. Volcanol. Geotherm. Res., 48, 103-113, 1991.

Cortini, M. and C.C. Barton, Nonlinear forecasting analysis of inflationdeflation patterns of an active caldera (Campi Flegrei, Italy), Geology, 21, 239-242, 1993.

Dixon, T. H, M. Bursik, S. Kornreich Wolf, M. Heflin, F. Webb, F. Farina, and S. Robaudo, Constraints on deformation of the resurgent dome, Long Valley Caldera, California from Space Geodesy, Contrib. of Space Geod. to Geodynamics: Crustal Dynamics, Geodynamics Series, 23, pp 193-214, 1993.

Dzurisin, D., Influence of fortnightly Earth tides at Kilauea volcano, Geophys. Res. Let., 7, 925-928, 1980.

Heflin, M., W. Bertiger, G. Blewitt, A. Freedman, K. Hurst, S. Lichten, U. Lindqwister, Y. Vigue, F. Webb, T. Yunck, and J. Zumberge, Global geodesy using GPS without fiducials, Geophy. Res. Lett., 19, pp. 131-134, 1992.

Hill, D. P., R. A. Bailey, and A. S. Ryall, Active tectonic and magmatic processes beneath Long Valley caldera, eastem California: a summary, Jour. Geophys. Res., 90, 11111-11120, 1985.

Hill, D. P., Ellsworth, W. L., Johnston, M. J. S., Langbein J. O., Oppenheimer, D.H., Pitt, A.M., Reasenberg, P.A., Sorey, M. L. and S. R. McNutt, The 1989 earthquake swarm beneath Mammoth Mountain, California: an initial look at the 4 May through 30 September activity, Bull. Seismo. Soc. Amer., 80, 325-339, 1990.

Langbein, J., The deformation of Long Valley Caldera, eastern California, from mid-1983 to mid-1988; measurements using a twocolor laser geodimeter, Jour. Geophys. Res., 94, 3833-3850, 1989.

Lichten, S. M., Estimation and filtering for high-precision GPS positioning applications, Manu. Geoda., 15, pp 159-176, 1990.

Langbein, J., D. P. Hill, T. N. Parker, and S. K. Wilkinson, An episode of reinflation of the Long Valley Caldera, eastern Califomia: 1989. 1991, Jour. Geophys. Res., 98, 15851-15870, 1993a.

Langbein, J., D. Dzurisin, G. Marshall, T. N. Parker, S. K. Wilkinson, M. Sorey, K. Yamashita, and J. Rundle, Modeling extension and uplift within the Long Valley Caldera; 1988-1992, EOS, Trans., Amer. Geophy. Union, Fall Meeting, 74, no. 43, pp 193, 1993b.

Press, W. H., S. A. Teukolsky, W. T. Vetterling, and B. P. Flannery, Numerical recipes in FORTRAN: The art of scientific computing, Cambridge University Press, Cambridge, 963p, 1992.

Yamashita, K. M., J. W. Kleinman, E. Y. Iwatsubo, J. W. Ewart, D. Dzurisin, J. B. Rundle, and R. S. Stein, Results of 1992 leveling survey at Long Valley caldera, California, EOS, Trans., Amer. Geophy. Union, 73, pp 347, 1992.

Zumberge, J., F. Webb, U. Lindqwister, S. Lichten, D. Jefferson, R Ibanez-Meier, M. Heflin, A. Freedman, and G. Blewitt, GPS data analysis for Earth orientation at the Jet Propulsion Laboratory, in Results from the SEARCH '92 Campaign, IERS Tech. Note \#16, eds. J.O. Dickey and M. Feissel, Cent. Bur. IERS - Obs. de Paris, 1994.

F. H. Webb, Jet Propulsion Laboratory, MS 238-600, California Institute of Technology, Pasadena, CA 91109. (e-mail: fhw@cobra.jpl.nasa.gov)

M. Bursik, Department of Geology, State University of New York, Buffalo, NY 14260

T. Dixon and F. Farina, Rosenstiel School of Marine and Atmospheric Science, Division of Marine Geology and Geophysics, University of Miami, 4600 Rickenbacker Causeway, Virginia Key, FL 33149

G. Marshall and R. S. Stein, U.S. Geological Survey, MS 977, 345 Middlefield Road, Menlo Park, CA 94025

(Received May 24, 1994; Accepted June 20, 1994.) 